\title{
SIFAT, KEPRIBADIAN, TUJUAN HIDUP MAHASISWA, DAN KAITANNYA DENGAN PERSEPSI TENTANG PERGAULAN LAWAN JENIS
}

\author{
Trait, Personality, Life Goal of College Students, and Its Relationship with Perception \\ about Interaction of Opposite Gender \\ MONIKA YULIANTIN ${ }^{1}$, HERIEN PUSPITAWATI' \\ MEGAWATI SIMANJUNTAK ${ }^{2^{*}}$ \\ ${ }^{1}$ Program Studi Gizi Masyarakat dan Sumberdaya Keluarga, Fakultas Pertanian, Institut \\ Pertanian Bogor, Kampus Dramaga, Bogor 16680 \\ ${ }^{2}$ Staf Pengajar Departemen Ilmu Keluarga dan Konsumen, Fakultas Ekologi Manusia, \\ Institut Pertanian Bogor, Jalan Lingkar Kampus IPB Dramaga, \\ Bogor 16680
}

\begin{abstract}
Globalization that develops in line with development of science and technology such as film, soap opera, and music do not only give positive influence but also have brought negative influence for Indonesian people who still extremely hold norms especially religion norm. The aimed of this research was to analyze the perception about interaction of opposite gender of college students. This research used cross sectional study design. The research was done in Bogor Agricultural University (IPB) Bogor. Respondents of this research were 146 students of undergraduate of $2^{\text {nd }}$ and $3^{\text {rd }}$ grade in the year 2008, consist of 43 men and 103 women. Almost all of respondents had conservative perception about interaction of opposite gender. The study found significant correlation between: (1) respondents perception about interaction of opposite gender with type of gender, cumulative achievement index, trait and personality, (2) interaction of opposite gender respondents' behaviour with type of gender, trait and personality, monthly pocket money, and respondents' perception about interaction of opposite gender. Multiple regression analysis showed that type of gender and trait and personality variables had significant effect on perception of interaction of opposite gender.
\end{abstract}

Key words: college students, life goal, opposite gender, perception, trait and personality

\section{PENDAHULUAN}

Era globalisasi dan informasi yang semakin terbuka sejalan dengan kemajuan ilmu dan teknologi (media elektronik, media cetak, dan lainnya) diantaranya film, sinetron, dan musik ternyata tidak hanya membawa pengaruh positif tapi juga membawa pengaruh negatif bagi bangsa Indonesia yang sangat menjunjung norma-norma terutama norma agama. Dampaknya terlihat pada perilaku masyarakat, terutama pada remaja yang masih mampu menyaring dan mengadopsi mana yang sesuai dengan nilai ketimuran.

Menurut Pangkahila (1997) sejak lebih dari satu dekade terakhir ini telah terjadi perubahan dalam pandangan dan perilaku seksual masyarakat, khususnya di kalangan remaja di Indonesia. Beberapa penelitian yang telah dilakukan di beberapa kota sejak tahun 1981 dengan kuat telah menunjukkan adanya perubahan itu. Pola pergaulan menjadi semakin bebas yang didukung oleh berbagai fasilitas, serta aktifitas seksual yang semakin mudah dilakukan dan bahkan mudah berlanjut menjadi hubungan seksual. Dapat diartikan pula bahwa hubungan seksual tidak lagi dianggap sebagai sesuatu yang sakral, yang hanya patut dilakukan dalam ikatan perkawinan. Ironisnya di sisi lain masyarakat, khususnya remaja, tidak menerima pendidikan seks yang benar dan bertanggung jawab.

Pengaruh lingkungan yang akhir-akhir ini meresahkan masyarakat adalah berkurangnya pengaruh norma pada perilaku masyarakat khususnya yang berkaitan 
dengan pergaulan lawan. Data studi empiris yang dilakukan melalui survei MCR-PKBI Jabar (Wiyana 2004), menunjukkan bahwa faktor-faktor yang mempengaruhi terjadinya hubungan seksual pranikah adalah faktor sulitnya mengendalikan dorongan seksual menduduki peringkat tertinggi $(63,68 \%)$, faktor kurang taat menjalankan agama $(55,79 \%)$, rangsangan seksual $(52,63 \%)$, sering menonton blue film $(49,47 \%)$, dan tidak ada bimbingan orangtua $(9,47 \%)$. Tiga faktor terakhir yang turut menyumbang hubungan seksual pranikah adalah pengaruh tren pergaulan $(24,74 \%)$, tekanan dari lingkungan $(18,42 \%)$, dan masalah ekonomi $(12,11 \%)$. Berbagai fenomena tersebut berpengaruh terhadap perubahan persepsi masyarakat tentang perilaku pergaulan bebas (dalam hal ini seksual) yang semakin menjadi hal biasa.

Berdasarkan fenomena di atas, maka dianggap perlu untuk meneliti seberapa jauh dampak dari globalisasi terutama pada pergaulan antar lawan jenis yang mengarah pada perilaku pergaulan yang menuju bebas pada mahasiswa. Hasilnya diharapkan dapat melindungi dari beberapa perilaku yang mengarah pada pergaulan bebas antar lawan jenis, seperti pada Undang-Undang Perlindungan Anak (Pasal 23 Tahun 2002), pada Rancangan Undang-Undang Anti Pornografi dan Pornoaksi, bahkan UndangUndang Kekerasan dalam Rumah Tangga yang berguna untuk remaja/dewasa, pendidik, dan masyarakat luas.

Penelitian ini bertujuan untuk mengetahui persepsi contoh tentang pergaulan lawan jenis. Sementara itu tujuan khususnya, yaitu: (1) mengetahui karakteristik contoh dan karakteristik keluarga contoh; (2) mengetahui tujuan hidup contoh dan persepsi contoh tentang pergaulan lawan jenis; (3) mengetahui hubungan antar variabel yang diteliti; dan (4) menganalisis faktor-faktor yang berpengaruh terhadap persepsi contoh terhadap pergaulan lawan jenis.

\section{METODE}

\section{Desain, Lokasi, dan Waktu}

Penelitian menggunakan desain cross sectional study dimana penelitian dilakukan hanya pada satu waktu tertentu (single period in time). Pengambilan data dilakukan di lingkungan kampus IPB Darmaga Kabupaten Bogor. Penentuan lokasi penelitian dilakukan secara purposive dengan pertimbangan memudahkan dalam pengambilan contoh sekaligus kevalidan data. Pengambilan data primer dilakukan pada bulan Maret hingga April 2008.

\section{Jumlah dan Teknik Penarikan Contoh}

Populasi penelitian ini adalah mahasiswa Institut Pertanian Bogor. Contoh dalam penelitian adalah 146 mahasiswa program sarjana (S1) IPB tingkat II dan III yang berasal dari Fakultas Ekologi Manusia dan mengambil mata kuliah Gender dan Keluarga pada Tahun Ajaran 2007/2008. Contoh dibedakan berdasarkan jenis kelamin, yaitu terdiri dari 43 laki-laki dan 103 perempuan sesuai dengan proporsi mahasiswa pada kelas mata kuliah Gender dan Keluarga. Pemilihan contoh dilakukan secara purposive berdasarkan pertimbangan bahwa keahlian yang dimiliki mahasiswa FEMA berhubungan dengan keadaan sosial dalam masyarakat.

\section{Jenis Data, Cara Pengumpulan Data, dan Pengukuran Variabel}

Jenis data yang diambil ada dua, yakni data primer dan data sekunder. Data primer diperoleh dengan wawancara langsung melalui kuesioner, yaitu: karakteristik contoh (umur, jenis kelamin, Indeks Prestasi Kumulatif, sifat, dan kepribadian), karakteristik keluarga contoh (umur orangtua, pendidikan orangtua, pekerjaan orangtua, pendapatan orangtua, uang saku bulanan contoh, nilai-nilai pergaulan berdasarkan nasihat orangtua), tujuan hidup contoh, dan persepsi tentang pergaulan antar lawan jenis sebelum menikah. Sementara itu, data sekunder meliputi jumlah mahasiswa IPB yang masuk dari tahun 2004 sampai dengan tahun 2005, yang terdiri dari laki-laki dan perempuan.

Pemberian skor pada variabel sifat dan kepribadian dilakukan dengan cara masingmasing pertanyaan diberi nilai satu jika jawabannya satu (sama sekali tidak benar), dan diberi nilai 7 bila semakin mendekati tujuh (selalu benar). Selanjutnya, direcode dahulu sifat dan kepribadian yang termasuk feminin/introvet, dari yang jawabannya satu diubah menjadi tujuh untuk disamakan dengan sifat dan kepribadian yang maskulin/ekstrovet. Berikutnya, skor ditotal dan dikelompokkan menjadi tiga kategori, yaitu semakin feminin/introvet (skor 66-198), feminin/introvet sama dengan maskulin/ekstrovet (skor 199-330), dan maskulin/ekstrovet (331-462). 
Untuk variabel tujuan hidup contoh, pemberian skor pertanyaan adalah jika jawabannya satu (sangat penting) maka bernilai tiga, jika jawabannya dua (kurang penting) maka bernilai dua, dan jika jawabannya tiga (tidak penting) maka bernilai satu. Kemudian skor ditotal dan dikelompokkan menjadi tiga kategori, yaitu tidak terarah (skor 28-47), kurang terarah (skor 48-66), dan sangat terarah (skor 6684).

Sementara itu, untuk variabel persepsi terhadap pergaulan lawan jenis, pemberian skor pada masing-masing pertanyaan adalah jika jawabannya satu (setuju) maka bernilai tiga, jawaban dua (netral) bernilai dua, dan jawaban tiga (tidak setuju) bernilai satu. Selanjutnya skor ditotal dan dikelompokkan menjadi tiga kategori, yaitu konservatif (skor 34-56,67), netral (skor 57-79,34), dan bebas (80-102).

\section{Pengolahan dan Analisis Data}

Data yang diperoleh kemudian diolah dengan menggunakan program Microsoft Excel dan SPSS, mencakup langkah-langkah transfer, coding, entry data, cleaning data, dan terakhir adalah analisis data. Data disajikan secara deskriptif dan menggunakan uji statistik inferensia berupa uji beda T-Test, uji korelasi Rank-Spearman, dan uji regresi berganda.

\section{HASIL DAN PEMBAHASAN}

\section{Karakteristik Contoh}

Usia dan Jenis Kelamin. Mahasiswa sebagai bagian dari remaja sering dianggap orang yang telah mencapai tingkat kedewasaan ketika mulai masuk dunia perguruan tinggi dan termasuk ke dalam masa remaja akhir 18-21 tahun (Monks et al. 1998 dalam Handayani 2001). Sementara itu, menurut Hurlock (1980), untuk usia 18-21 tahun termasuk ke dalam usia dewasa dini, yang mana usia dewasa dimulai pada usia 18 tahun sampai kira-kira 40 tahun.

Rentang usia contoh adalah 18-20 tahun dan 21-23 tahun. Lebih dari tiga perempat $(76,8 \%)$ contoh berada pada rentang usia 18-20 tahun. Hasil juga menunjukkan bahwa hampir tiga perempat $(70.5 \%)$ contoh berjenis kelamin perempuan dan hampir sepertiga $(29,5 \%)$ contoh berjenis kelamin laki-laki.

Indeks Prestasi Kumulatif (IPK) Contoh. Sebaran Indeks Prestasi Kumulatif (IPK) contoh berkisar dari 2,00 sampai dengan 3,86 dengan rata-rata Indeks Prestasi Kumulatif 2,93. Namun apabila dibedakan berdasarkan jenis kelamin, Indeks Prestasi Kumulatif yang dimiliki contoh lakilaki berada pada kisaran 2,00-3,82 dan pada perempuan berada pada kisaran 2,00-3,86. Meskipun demikian, jika dilihat dari uji beda, hasilnya tidak berbeda secara nyata antara rata-rata Indeks Prestasi Kumulatif (IPK) dari contoh perempuan $(2,95)$ dan laki-laki $(2,88)$.

\section{Karakteristik Keluarga Contoh}

Usia Orangtua. Sebaran usia orangtua contoh antara 33 tahun sampai dengan 64 tahun. Lebih dari tiga perempat $(77,4 \%)$ ayah contoh mempunyai usia pada rentang 41-55 tahun, dengan rata-rata usia 48,83 tahun. Demikian halnya dengan usia ibu contoh, terlihat bahwa sebagian besar $(82,2 \%)$ usia ibu termasuk ke dalam rentang 41-55 tahun, dengan rata-rata usia 46,02 tahun.

Hasil di atas menjelaskan bahwa kebanyakan usia orangtua baik dari ayah maupun ibu, termasuk ke dalam usia dewasa madya (41-65 tahun). Orangtua yang usianya masuk ke dalam kategori dewasa madya biasanya dapat membantu anak remajanya untuk menjadi orang dewasa yang bertanggung jawab dan bahagia (Hurlock 1980).

Pendidikan Orangtua. Pendidikan orangtua menyebar dari tidak tamat SD sampai dengan sekolah pasca sarjana (S2S3). Persentase terbanyak ayah contoh (39\%) dan ibu contoh $(40,4 \%)$ adalah menamatkan pendidikan di jenjang pendidikan SLTA. Hanya 4,1\% ayah contoh tidak menamatkan pendidikan di jenjang SD, dan terdapat $4,1 \%$ ibu contoh telah menamatkan pendidikan S2-S3.

Pekerjaan Orangtua. Pekerjaan orangtua beraneka ragam mulai dari PNS/ABRI, pegawai swasta/BUMN/ pengacara, petani/buruh, wiraswasta, ibu rumah tangga/tidak bekerja, pensiunan/ pemuka agama, dan not applicable/ almarhum. Hasil penelitian menunjukkan bahwa ayah contoh sebagai PNS/ABRI adalah merupakan persentase terbesar $(36,3 \%)$, sedangkan persentase terbesar $(56,3 \%)$ status pekerjaan ibu contoh adalah tidak bekerja atau sebagai ibu rumah tangga.

Pendapatan Orangtua. Pendapatan orangtua berkisar antara kurang dari Rp 500.000 sampai dengan lebih besar dari Rp 2.500.000,00. Hasil penelitian menunjukkan bahwa proporsi terbesar total pendapatan orangtua (keluarga) contoh 
adalah di atas Rp 2.500.000,00 per bulan. Kondisi ekonomi keluarga yang kurang akan berpengaruh terhadap kondisi mental dan psikis individu yang hidup dalam keluarga (Gunarsa \& Gunarsa 2000).

Uang Saku Bulanan. Uang saku bulanan contoh berkisar antara Rp 150.000,00 sampai dengan $R p$ 2.000.000,00, sedangkan uang saku rata-rata yang diberikan kepada contoh adalah $\mathrm{Rp} 578.595,89$. Berdasarkan hasil uji beda tidak didapatkan hasil yang signifikan yang terlihat pada contoh laki-laki maupun perempuan yang sama-sama mendapatkan uang saku dengan persentase terbesar pada kurang dari sama dengan Rp 500.000,00, yaitu lebih dari separuh baik contoh laki-laki $(51,2 \%)$ dan perempuan $(53,4 \%)$.

\section{Sifat dan Kepribadian Contoh}

Sifat dan kepribadian contoh dibagi menjadi tiga golongan, cenderung Feminin/Introvet, Feminin/Introvet=Maskulin/ Ekstovet, dan cenderung Maskulin/Ekstrovet. Pada Tabel 1 dapat dilihat bahwa seluruh $(100 \%)$ contoh mempunyai sifat yang seimbang antara Feminin/Introvet dan Maskulin/Ekstovet. Hasil penelitian ini sesuai dengan pendapat Berns (1997) dalam Wahini (2001) yang menyebutkan karakteristik feminin (seperti lembut, manja, perasa, sensitif, penuh perhatian, penuh rasa cinta) berhubungan sangat erat dengan perempuan, sedangkan karakteristik maskulin (seperti berkepribadian keras, tegas, kerja keras, senang berkompetisi, punya rencana yang sistematis, kurang sensitif) berhubungan sangat erat dengan laki-laki. Uji beda $t$ tidak menunjukkan perbedaan yang signifikan pada sifat \& kepribadian antara contoh laki-laki dan perempuan $(p>0,1)$

\section{Tujuan Hidup Contoh}

Berdasarkan hasil penelitian, diketahui bahwa dari seluruh pernyataan tujuan hidup, yaitu 26 dari 28 pernyataan dianggap sangat penting, misalnya meneruskan ke program master/doktor, mempunyai rumah sendiri, mempunyai uang banyak, menjadi direktur sebuah perusahaan, mempunyai perkawinan yang bahagia, mempunyai status sosial di masyarakat, mempunyai keluarga yang sakinah, menjadi pemimpin masyarakat, menjadi pemimpin keluarga, mempunyai anak-anak yang soleh, bekerja keras dan belajar tekun, menabung dan hidup hemat, menghindari masalah di kampus, menghindari obat-obat terlarang, menghindari minuman keras, menjadi manusia yang soleh, beramal soleh, berbakti pada orangtua, membahagiakan anak yatim, bertanggung jawab atas perbuatan kita, menghormati orang lain, berteman yang baik, penyayang pada semua mahluk hidup, beraktivitas di kampus dengan baik, menjadi ibu/ayah atau istri/suami yang baik dan mengejar karir/pekerjaan yang mapan sampai tua. Sementara itu, tujuan yang dianggap tidak penting adalah menghalalkan segala cara untuk mencapai tujuan dan hidup untuk bersenang-senang. Berdasarkan uji beda t terdapat tiga tujuan, yaitu tujuan menjadi direktur sebuah perusahaan, menjadi pemimpin masyarakat, dan menjadi pemimpin keluarga yang berbeda antara contoh laki-laki dengan perempuan dengan skor lebih tinggi pada contoh laki-laki. Hal ini diduga karena keyakinan umum tentang perbedaan jenis kelamin dan peran yang harus dijalankan, dimana hal tersebut lebih memperlihatkan adanya tekanan sosial yang lebih besar pada anak laki-laki agar bertingkah laku sesuai dengan perannya yang juga dianggap lebih penting daripada anak perempuan (Hawadi 2001). Sementara itu, tujuan hidup menghindari masalah di kampus cenderung lebih dipegang perempuan dibandingkan laki-laki karena laki-laki cenderung lebih agresif dibandingkan perempuan.

Tabel 1. Sebaran contoh berdasarkan sifat dan kepribadian

\begin{tabular}{|c|c|c|c|c|c|c|}
\hline \multirow{2}{*}{ Sifat Kepribadian } & \multicolumn{2}{|c|}{ Laki-laki } & \multicolumn{2}{|c|}{ Perempuan } & \multicolumn{2}{|c|}{ Total } \\
\hline & $\mathbf{n}$ & $\%$ & $\mathbf{n}$ & $\%$ & $\mathbf{n}$ & $\%$ \\
\hline Cenderung Feminin/Introvet (66-198) & 0 & 0,0 & 0 & 0,0 & 0 & 0 \\
\hline Feminin/Introvet=Maskulin/Ekstrovet (199-330) & 43 & 100,0 & 103 & 100,0 & 146 & 100,0 \\
\hline Cenderung Maskulin/Ekstrovet (331-462) & 0 & 0,0 & 0 & 0,0 & 0 & 0 \\
\hline Total & 43 & 100,0 & 103 & 100,0 & 146 & 100,0 \\
\hline Rata-rata skor & &, 50 & & & & \\
\hline Skor minimum & & & & & & \\
\hline Skor maksimum & & & & & & \\
\hline Uji beda-t (sig) & & & & & & \\
\hline
\end{tabular}


Berdasarkan skor komposit tujuan hidup contoh (Tabel 2), diketahui bahwa hampir seluruh contoh $(97,9 \%)$ mempunyai tujuan hidup yang sangat terarah. Meskipun demikian, bagi contoh perempuan tujuan hidupnya tersebar dari yang tidak terarah sampai dengan terarah (skor 34-84), sedangkan bagi contoh laki-laki tersebar dari kurang terarah sampai terarah (skor 65-84). Berdasarkan hasil ini disimpulkan bahwa secara umum contoh menginginkan kehidupan lebih baik dan terarah di masa depan, namun tidak ada perbedaan tujuan hidup antara contoh laki-laki dan perempuan $(p=0,552)$.

\section{Persepsi Contoh tentang Pergaulan Lawan Jenis \\ Hasil penelitian menunjukkan bahwa} terdapat enam item persepsi yang disetujui oleh contoh, yaitu pendidikan seks di SD, pendidikan seks di SMP/SMA, laki-laki harus menyatakan cinta lebih dahulu, ngobrol dan berbicara/curhat antara laki-laki dan perempuan, laki-laki harus dalam keadaan perjaka saat menikah, dan perempuan harus dalam keadaan perawan saat menikah. Selanjutnya terdapat lima item persepsi yang dikatakan dapat dilakukan atau tidak/ tergantung situasi dan kondisi oleh contoh, yaitu kawin muda sebelum lulus sekolah/ perguruan tinggi, perempuan boleh menyatakan cinta dahulu kepada laki-laki, sekedar berjalan berdekatan, sekedar bergandengan tangan dengan lawan jenis, dan berjalan berdua laki-laki dan perempuan. Adapun hal-hal yang tidak setujui oleh contoh, adalah ATM kondom, iklan kondom dan obat-obat perangsang di TV, iklan yang menjurus pornografi dan pornoaksi, hidup bersama sebelum menikah, kawin paksa oleh orangtua, kawin kontrak selama waktu tertentu dengan orang asing, berciuman pipi dengan lawan jenis, berpelukan dengan lawan jenis, berciuman bibir dengan lawan jenis, laki-laki dan perempuan pulang malam (di atas jam 23.00), melakukan seks oral dengan lawan jenis, melakukan hubungan seks lawan jenis, seks bebas di kalangan remaja, hubungan homo (laki-laki dengan laki-laki), hubungan lesbian (perempuan dengan perempuan), perempuan merupakan obyek seksual, perasaan cinta yang total adalah cinta dengan melakukan seksual, aborsi bagi perempuan belum menikah, dan boleh melakukan hubungan badan pacar asal tidak melakukan hubungan seks.

Apabila contoh dikelompokkan menjadi tiga golongan, yaitu konservatif, netral, dan bebas (Tabel 3), maka hampir seluruh contoh $(92,5 \%)$ memiliki persepsi tentang pergaulan lawan jenis semakin konservatif dan hanya sebagian kecil saja yang tergolong netral $(7,5 \%)$. Dengan demikian,

Tabel 2. Sebaran contoh berdasarkan kategori tujuan hidup contoh

\begin{tabular}{|c|c|c|c|c|c|c|}
\hline \multirow{3}{*}{ Tujuan hidup } & \multicolumn{4}{|c|}{ Jenis kelamin } & \multirow{2}{*}{\multicolumn{2}{|c|}{ Total }} \\
\hline & \multicolumn{2}{|c|}{ Laki-laki } & \multicolumn{2}{|c|}{ Perempuan } & & \\
\hline & $\mathbf{n}$ & $\%$ & $\mathbf{n}$ & $\%$ & $\mathbf{n}$ & $\%$ \\
\hline Tidak terarah (28-47) & 0 & 0,0 & 1 & 1,0 & 1 & 0,7 \\
\hline Kurang terarah (48-66) & 2 & 4,7 & 0 & 0,0 & 2 & 1,4 \\
\hline Sangat terarah (66-84) & 41 & 95,3 & 102 & 99,0 & 143 & 97,9 \\
\hline Total & 43 & 100,0 & 103 & 100,0 & 146 & 100,0 \\
\hline Rata-rata skor & & & & & & \\
\hline Min & & & & & & \\
\hline Max & & & & & & \\
\hline Uji beda t (sig) & & & & & & \\
\hline
\end{tabular}

Tabel 3. Sebaran contoh berdasarkan persepsi tentang pergaulan lawan jenis

\begin{tabular}{|c|c|c|c|c|c|c|}
\hline \multirow{2}{*}{ Persepsi Tentang Pergaulan Lawan Jenis } & \multicolumn{2}{|c|}{ Laki-laki } & \multicolumn{2}{|c|}{ Perempuan } & \multicolumn{2}{|c|}{ Total } \\
\hline & n & $\%$ & $\mathbf{n}$ & $\%$ & $\mathbf{n}$ & $\%$ \\
\hline Konservatif (34-56.67) & 36 & 83,7 & 99 & 96,1 & 135 & 92,5 \\
\hline Netral (57-79.34) & 7 & 16,3 & 4 & 3,9 & 11 & 7,5 \\
\hline Bebas (80-102) & 0,0 & 0,0 & 0 & 0,0 & 0 & 0,0 \\
\hline Total & 43 & 100,0 & 103 & 100,0 & 146 & 100,0 \\
\hline $\begin{array}{c}\text { Rata-rata skor } \\
\text { Min } \\
\text { Max } \\
\text { Uji beda t (sig) }\end{array}$ & & & & & & \\
\hline
\end{tabular}


contoh penelitian dapat dikatakan masih memegang teguh norma dan nilai agama dengan kuat. Meskipun demikian, berdasarkan uji beda $\mathrm{t}$ antar jenis kelamin, didapatkan hasil bahwa contoh laki-laki lebih memiliki persepsi tentang pergaulan lawan jenis yang lebih bebas $(49,09)$ dibandingkan perempuan $(44,39)$. Hal ini membenarkan bahwa laki-laki cenderung lebih permisif sehingga persepsinya lebih mengarah ke liberal (bebas) dibandingkan perempuan (cenderung konservatif).

\begin{tabular}{cccc}
$\begin{array}{l}\text { Hubungan } \\
\text { Penelitian }\end{array}$ & Antar & \multicolumn{2}{c}{ Variabel-Variabel } \\
Hasil uji & korelasi & Rank & Spearman \\
menunjukkan & bahwa & jenis & kelamin
\end{tabular}
berhubungan negatif dengan sifat dan kepribadian ( $\left.r=-0,346^{\star * *}\right)$. Artinya bahwa contoh laki-laki semakin mempunyai sifat maskulin/ekstrovet sedangkan perempuan semakin mempunyai sifat feminin/introvet.

Sementara itu, beberapa variabel menunjukkan hubungan yang nyata yaitu pendidikan ayah berhubungan positif dengan pendidikan ibu $\left(r=0,492^{* * *}\right)$; pendidikan ibu berhubungan positif dengan pekerjaan ibu $\left(r=0,418^{* * *}\right)$; uang saku bulanan berhubungan positif dengan pendidikan ayah $\left(r=0,360^{* * *}\right)$; berhubungan positif dengan pendidikan ibu $\left(r=0,257^{* * *}\right)$; dan berhubungan positif dengan pekerjaan ayah $\left(r=0,149^{*}\right)$. Penelitian ini juga menunjukkan bahwa ayah yang berpendidikan tinggi cenderung memiliki istri yang berpendidikan tinggi pula (ibu contoh). Selain itu, juga ditemukan bahwa ibu yang berpendidikan tinggi cenderung lebih memilih bekerja disbandingkan tidak bekerja. Sementara itu, semakin besar uang saku bulanan yang diterima contoh, ayah dan ibunya cenderung berpendidikan tinggi dan juga ayahnya bekerja.

Hasil penelitian ini juga menunjukkan bahwa tujuan hidup contoh berhubungan negatif dengan Indeks Prestasi Kumulatif (IPK) $\quad\left(r=-0,142^{*}\right)$, berhubungan positif dengan sifat dan kepribadian $\left(r=0,182^{* *}\right)$, dan berhubungan negatif dengan pekerjaan ayah $\left(r=-0,184^{*}\right)$. Hal ini dapat diartikan bahwa tujuan hidup seseorang yang semakin terarah (tujuan sudah direncanakan dengan lebih baik) cenderung ditemukan pada contoh yang memiliki Indeks Prestasi Kumulatif (IPK) rendah, ditemukan pada contoh yang memiliki sifat dan kepribadian maskulin/ekstrovet, dan ditemukan pada contoh yang ayahnya bekerja.

Persepsi contoh tentang pergaulan lawan jenis pada penelitian ini juga berhubungan negatif dengan jenis kelamin $\left(r=-0,360^{* * *}\right)$, berhubungan positif dengan Indeks Prestasi Kumulatif (IPK) $\left(r=0,153^{*}\right)$, serta sifat dan kepribadian $\left(r=0,180^{* *}\right)$. Hasil tersebut menunjukkan bahwa persepsi contoh tentang pergaulan lawan jenis yang semakin bebas cenderung berasal dari lakilaki, cenderung ditemukan pada contoh yang mempunyai indeks prestasi kumulatif yang lebih tinggi, dan cenderung ditemukan pada contoh yang memiliki sifat dan kepribadian maskulin/ekstrovet.

\section{Faktor-Faktor yang Mempengaruhi} Persepsi terhadap Pergaulan Lawan Jenis

Hasil uji statistik regresi linier berganda pada Tabel 4 , menunjukkan bahwa variabel yang berpengaruh terhadap persepsi tentang pergaulan lawan jenis sebelum menikah adalah jenis kelamin laki-laki $\left(\beta=-0,350^{* * *}\right)$

Tabel 4. Faktor-faktor yang berpengaruh pada persepsi pergaulan lawan jenis

\begin{tabular}{|c|c|c|c|}
\hline Variabel & $\beta$ & $\mathbf{t}$ & $\mathbf{P}$ \\
\hline Jenis kelamin $(1=\mathrm{L} ; 2=\mathrm{P})$ & $-0,350$ & $-4,316$ & $0,000^{* *}$ \\
\hline Indeks Prestasi Kumulatif (skor) & 0,128 & 1,642 & 0,103 \\
\hline Pendidikan ayah (tahun) & 0,054 & 0,597 & 0,552 \\
\hline Pendidikan Ibu (tahun) & $-0,050$ & $-0,583$ & 0,561 \\
\hline Uang saku (Rupiah) & 0,058 & 0,703 & 0,483 \\
\hline Tujuan hidup (skor) & $-0,068$ & $-0,868$ & 0,387 \\
\hline Sifat dan kepribadian (skor) & 0,149 & 1,808 & $0,073^{*}$ \\
\hline$F(p)$ & \multicolumn{3}{|c|}{$4,769\left(0,000^{\star \star *}\right)$} \\
\hline$R^{2}$ Adj & \multicolumn{3}{|c|}{0,154} \\
\hline Df & \multicolumn{3}{|c|}{145} \\
\hline $\mathrm{N}$ & \multicolumn{3}{|c|}{146} \\
\hline
\end{tabular}

\footnotetext{
Keterangan :

$\mathrm{R}^{2}$ Adj = Adjusted R-square

* $\quad=$ Berpengaruh nyata pada $\alpha=10 \%$

** $\quad=$ Berpengaruh nyata pada $\alpha=1 \%$
} 
dan sifat dan kepribadian maskulin/ekstrovet $\left(\beta=0,149^{*}\right)$ dengan adjusted $R$ square 0,154. Hasil tersebut diperkuat hasil uji korelasi sebelumnya yang menyatakan bahwa jenis kelamin dan sifat dan kepribadian mempunyai hubungan nyata dengan persepsi tentang pergaulan lawan jenis sebelum menikah. Hasil regresi ini kemudian menjelaskan bahwa bila contoh adalah perempuan maka persepsi pergaulan lawan jenisnya cenderung lebih konservatif, sebaliknya apabila contoh laki-laki maka persepsi tentang pergaulan lawan jenisnya cenderung lebih bebas. Persepsi tentang pergaulan lawan jenis contoh laki-laki yang lebih mengarah ke pergaulan bebas diduga dikarenakan perbedaan persepsi tentang pergaulan antara laki-laki-laki dan perempuan. Hasil ini sesuai dengan pendapat Brizendine (2006), dan Pangkahila (2007), yang menyatakan baik dari perkembangan otak/hormon (testosteron membuat laki-laki lebih banyak berpikir atau agresif tentang seks), sifat (agresif, keras, kasar, kurang peduli), dan lingkungan (budaya/nilai-nilai yang membentuknya), lakilaki cenderung lebih agresif termasuk tentang seksual (pergaulan lawan jenis), sehingga persepsi laki-laki menjadi lebih permisif pada pergaulan yang lebih bebas. Hal ini diduga juga dikarenakan perbedaan budaya/pandangan masyarakat di sekitarnya atau hasil konstruksi sosial budaya (UNFPA 2005).

\section{KESIMPULAN DAN SARAN}

\section{Kesimpulan}

Contoh penelitian ini adalah 146 mahasiswa yang terdiri dari 103 mahasiswa perempuan dan 43 mahasiswa laki-laki dengan kisaran usia antara 18-23 tahun, dengan rata-rata IPK 2,93, dan memiliki sifat dan kepribadian yang tidak berpihak pada stereotip tertentu (sama-sama memiliki feminin/introvet dan maskulin/ekstrovet). Tujuan hidup contoh sudah tergolong terarah mencakup meneruskan ke program master, perkawinan yang bahagia, menjadi pemimpin masyarakat hingga menjadi orangtua yang baik. Persepsi contoh perempuan tentang pergaulan lawan jenis adalah konservatif, sementara contoh laki-laki cenderung liberal. Sebagian besar contoh sudah cukup puas dengan kehidupannya.

Berdasarkan uji korelasi Rank Spearman disimpulkan: (1) contoh laki-laki cenderung bersifat/kepribadian maskulin/ ekstrovet, sedangkan contoh perempuan cenderung bersifat/kepribadian feminin/ introvet; (2) pendidikan ayah yang tinggi cenderung berhubungan dengan pendidikan ibu yang tinggi, begitu pula dengan sebaliknya; (3) ibu yang pendidikan tinggi cenderung bekerja, sedangkan apabila pendidikan ibu rendah ibu tidak bekerja; (4) uang saku bulanan contoh semakin besar apabila ayah berpendidikan lebih tinggi, ibu berpendidikan tinggi, dan ayah bekerja; (5) semakin terarah tujuan hidup contoh, semakin tinggi Indeks Prestasi Kumulatif (IPK), sifat dan kepribadian cenderung maskulin/ekstrovet, dan ayah bekerja; dan (6) persepsi tentang pergaulan lawan jenis cenderung bebas lebih tinggi pada contoh laki-laki, IPK cenderung tinggi, mempunyai sifat dan kepribadian cenderung maskulin/ekstrovet.

Hasil uji statistik regresi linier berganda, menunjukkan bahwa faktor yang berpengaruh nyata terhadap persepsi tentang pergaulan lawan jenis sebelum menikah adalah faktor jenis kelamin dan sifat dan kepribadian.

\section{Saran}

Perlu dilakukan uji hubungan atau pengaruh antara nilai-nilai keluarga dengan persepsi pergaulan lawan jenis, karena diduga mempengaruhi persepsi tentang pergaulan lawan jenis atau pendidikan ibu dengan nilai-nilai keluarga, dimana penanaman nilai-nilai diduga akan mempengaruhi pergaulannya di masa yang akan datang.

\section{DAFTAR PUSTAKA}

Brizendine L. 2006. Female Brain. Jakarta: Ufuk Press.

Gunarsa SD, Gunarsa YSD. 2000. Psikologis Praktis: Anak, Remaja, dan Keluarga. Jakarta: BPK Gunung Mulia.

Handayani MN. 2001. Perkembangan Psikologi Remaja. http://www.iqeq.web. id. [5 Mei 2006].

Hawadi RA. 2001. Psikologi Perkembangan Anak. Jakarta: Gramedia Widiasarana.

Hurlock E. 1980. Psikologi Perkembangan, Suatu Pendekatan Sepanjang Rentang Kehidupan. Edisi Kelima. Jakarta: Erlangga.

Pangkahila W. 1997. Perilaku Remaja di Desa dan di Kota [artikel]. http://www.google.com. [06 Maret 2008]. 
2007. Membangun Karakter Seksual dan Gender Anak Sejak Dini [artikel]. http://www.google.com. [06 Maret 2008].

UNFPA. 2005. Bunga Rampai: Panduan dan Bahan Pembelajaran Pelatihan Pengarusutamaan Gender dalam Pembangunan Nasional. Jakarta.

Wahini M. 2001. Hubungan Pola Asuh Penerimaan-Penolakan dengan Kepribadian Anak Pada Keluarga Perkotaan dan Pedesaan (Studi Kasus di Kelurahan Bantarjati dan Desa Leuwiliang-Bogor) [tesis]. Bogor: Institut Pertanian Bogor.

Wiyana. 2004. Free Seks Remaja Bandung Mengkhawatirkan. $\quad$ http://www. tempointeraktif.com. [27 November 2007].

* Korespondensi :

Telp : +62-2518628303

Email : mega_juntak@yahoo.com 